\title{
Aqueous Thick-Film Ceramic Processing of Planar Solid Oxide Fuel Cells using La0.20Sr0.25Ca0.45TiO3 Anode Supports
}

\author{
R. Price a , C. D. Savaniu a ${ }^{\text {a M. Cassidy }}{ }^{\text {a }}$ and J. T. S. Irvine ${ }^{\text {a }}$ \\ ${ }^{\text {a }}$ School of Chemistry, University of St Andrews, St Andrews, Fife, KY16 9ST, UK
}

\begin{abstract}
Recent research into the upscaling and implementation of $\mathrm{Rh} / \mathrm{Ce}_{0.80} \mathrm{Gd}_{0.20} \mathrm{O}_{1.90} \quad$ co-impregnated $\mathrm{La}_{0.20} \mathrm{Sr}_{0.25} \mathrm{Ca}_{0.45} \mathrm{TiO}_{3}$ $\left(\mathrm{LSCT}_{\mathrm{A}-}\right)$ anodes in electrolyte-supported SOFC at short-stack industrial scales has resulted in extremely robust performance under realistic operation and tolerance to harsh conditions. Furthermore, evaluation of the mechanical strength of $\mathrm{LSCT}_{\mathrm{A}}$ and incorporation of this material into anode-supported SOFC also yielded promising performance at the button cell scale (using $\mathrm{Ni}$ and $\mathrm{CeO}_{2}$ catalyst impregnates). The knowledge on ceramic processing obtained during these previous research campaigns may be used to develop anode-supported SOFC with LSCT $_{\mathrm{A}-}$ 'backbones' that have been optimised for high mechanical strength, high 'effective' electronic conductivity and sufficient porosity. Therefore, this manuscript details the preparation of anode-supported SOFC using the thickfilm ceramic processing technique of aqueous tape casting, the optimisation of anode microstructure through addition of aqueous solvent-compatible graphitic and methacrylate polymer pore formers and the co-sintering of a $\mathrm{LSCT}_{\mathrm{A}}$ - support with a typical SOFC electrolyte material.
\end{abstract}

\section{Introduction}

Solid Oxide Fuel Cells (SOFC) may be used to generate an electrical current (in addition to heat) through an electrochemical fuel oxidation process at operating temperatures between $600{ }^{\circ} \mathrm{C}$ and $850^{\circ} \mathrm{C}(1,2)$. This useful co-generation of heat and electricity is highly efficient $(1,3)$, regardless of the scale of generation, for example in micro-combined heat and power ( $\mu$-CHP) systems (with power outputs of $1-5 \mathrm{~kW}$, for use in small family homes and businesses), as well as in large scale 'power plants' for electricity conversion $(>50 \mathrm{~kW}$ power output) (2).

Large scale SOFC stack testing and successful market introduction of some SOFCbased units by a number of industrial companies has been realised over the past decade. The SOFC employed within these larger scale stacks typically comprise a set of 'traditional' materials, for example: Ni-based ceramic-metal composite (cermet) anodes (4-6), stabilised zirconia (5) or substituted-ceria electrolytes (7) and cathodes comprising lanthanum strontium manganite and yttria-stabilised-zirconia (LSM-YSZ) (8-10) or lanthanum strontium cobaltite ferrite and cerium gadolinium oxides (LSCF-CGO) $(9,11-$ 15). Although, successful production and operation of these SOFC stacks has been achieved, the Ni-based cermet anode exhibits several undesirable properties which can give rise to limited performance and durability and must be circumnavigated by advanced 
engineering solutions (16). For example, when exposed to RedOx cycling treatments, unprocessed and sulphurised fuel gases and extremely high fuel utilisation/overload conditions, this type of anode can often suffer irreversible damage, leading to rapid degradation of SOFC performance $(3,16)$. Therefore, in order to reduce the cost of the overall system, alternative anode materials that are less sensitive to harsh operational conditions are sought to address these challenges.

Research into the use of $\mathrm{Rh}$ and $\mathrm{Ce}_{0.80} \mathrm{Gd}_{0.20} \mathrm{O}_{1.90}$ (CGO20) co-impregnated $\mathrm{La}_{0.20} \mathrm{Sr}_{0.25} \mathrm{Ca}_{0.45} \mathrm{TiO}_{3}\left(\mathrm{LSCT}_{\mathrm{A}}\right)$ anodes, as replacements for the traditional Ni-based cermets, in electrolyte-supported SOFC has yielded extremely impressive durability and robustness at industrial short stack scales over the past decade. These anodes have exhibited the ability to rival the degradation and RedOx/thermal/thermo-RedOx cycling tolerance of state-of-the-art SOFC anodes at short stack scales, in addition to providing the ability to operate under sulphur-laden fuel gas streams and high fuel utilisation/overload conditions (17).

Given the success of implementation of LSCT $_{\mathrm{A}-\text { anodes into Electrolyte Supported Cells }}$

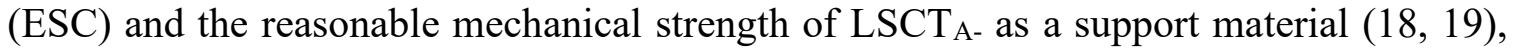
successful attempts have also been made to employ $\mathrm{LSCT}_{\mathrm{A}-}$ as an anode support for SOFC at button cell scales $(20,21)$, in addition to appraisal of the upscaling of thick-film ceramic processing techniques used to prepare larger $(20 \mathrm{~cm}$ by $20 \mathrm{~cm}) \mathrm{SOFC}$ anode supports (19). These studies performed by Lu et al., Ni et al. and Verbraeken et al. (19-21) focussed upon production of $\mathrm{LSCT}_{\mathrm{A}-}$ anode supports by aqueous tape casting followed by either cocasting or screen printing of an $8 \mathrm{~mol}$. \% yttria-stabilised-zirconia (8YSZ) electrolyte layer.

Therefore, using these studies as a basis for the current research, we present results concerning the ceramic processing of Anode Supported Cells (ASC), that employ LSCT $\mathrm{A}$ anode 'backbone' microstructures, using $\mathrm{LSCT}_{\mathrm{A}-}$ powders produced commercially on kilogram-scale at industrial pilot plants. The ultimate aim of this research is to test ASC

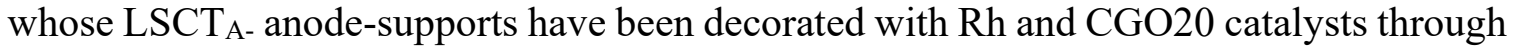
wet impregnation. Here, we detail a thermal compatibility study of a variety of electrode and electrolyte material sets using dilatometric analysis, in order to identify electrolyte and anode materials whose shrinkages are sufficiently matched to allow co-sintering of the two

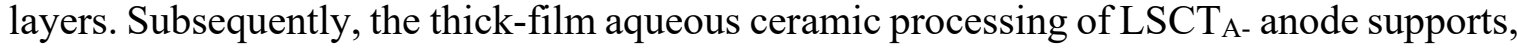
via tape casting, is discussed. In addition, the most appropriate method to produce dense electrolyte layers (i.e. electrolyte deposition by co-casting or screen printing), is appraised, with the aim of co-sintering anode-electrolyte structures up to temperatures of $1400{ }^{\circ} \mathrm{C}$ in air. Finally, an evaluation of the microstructural characteristics of $\mathrm{LSCT}_{\mathrm{A}}$ - supports, prepared using a typical graphite pore former (commonly used with organic solvent systems) or without the use of a pore former, will be provided and compared to microstructures resulting from the incorporation of poly(ethyl/methyl methacrylate) pore formers that are compatible with the aqueous solvent system employed (22). 


\section{Experimental}

$\underline{\text { Particle Size and Dilatometric Analysis of Anode and Electrolyte Materials }}$

Particle size analysis (PSA) was performed for the following materials: Treibacher $\mathrm{La}_{0.20} \mathrm{Sr}_{0.25} \mathrm{Ca}_{0.45} \mathrm{TiO}_{3}\left(\mathrm{TLSCT}_{\mathrm{A}}\right.$-, Treibacher Industrie AG), Praxair $\mathrm{LSCT}_{\mathrm{A}-}\left(\mathrm{PLSCT}_{\mathrm{A}}\right.$, Praxair Specialty Ceramics), 8 molar \% (mol. \%) yttria-stabilised-zirconia (8YSZ, Daiichi Kigenso Kagaku Kogyo Co. Ltd.), 6 mol. \% scandia-stabilised-zirconia (6ScSZ, HEXIS) and $6 \mathrm{~mol}$ \% scandia, $1 \mathrm{~mol}$ \% ceria-stabilised-zirconia (6Sc1CeSZ, Unitec). The analysis was carried out using a Malvern Mastersizer 2000 Particle Size Analyser, employing Hypermer KD6 (Croda Europe Ltd.) as a dispersant and deionised water as a solvent. Additionally, a portion of the TLSCT $\mathrm{A}_{\mathrm{A}}$ powder was subjected to high-speed planetary ball milling to reduce the particle size $\left(\mathrm{d}_{50}\right)$ and increase sinteractivity. This treatment was performed using $2 \mathrm{~mm}$ diameter zirconia milling media at $900 \mathrm{rpm}$ for 3 hours. The particle size distribution of this 'Milled TLSCT $_{\mathrm{A}-}$ ' powder was also determined using the aforementioned protocol.

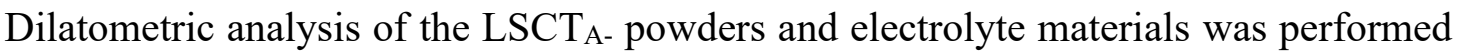
using a Netzsch DIL 402 dilatometer. Each material was pressed to form a $7 \mathrm{~mm}$ diameter pellet using a mass of 2 Tonnes for 60 seconds. The 'green' pellets (or a pre-sintered alumina pellet, used for the correction run) were then placed into the sample holder of the dilatometer, with an alumina spacer on either side, and the push rod was positioned to contact the first alumina spacer. The shrinkage of each sample was measured during heating to $1350^{\circ} \mathrm{C}$ at a rate of $3{ }^{\circ} \mathrm{C} \mathrm{min}^{-1}$, followed by a 3 hour dwell, then cooling to room

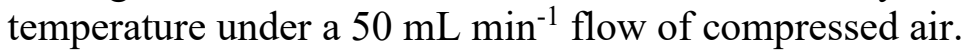

\section{Aqueous Slurry Formulation, Rheological Analysis and Tape Casting}

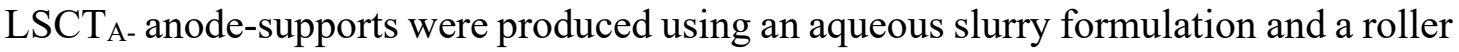

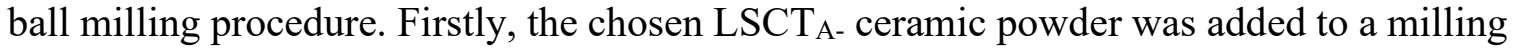
vessel with $3010 \mathrm{~mm}$ diameter zirconia milling media, deionised water (as a solvent), a Hypermer KD6 dispersant and a 2, 4, 7, 9 tetramethyl(5-decyne) 4, 7 diol ethoxylate defoamer (DF002, Polymer Innovations). In addition, pore formers were added to specific formulations during the dispersion milling step to give a $30 \mathrm{wt} . \%$ loading with respect to

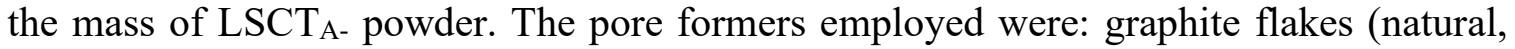
325 mesh, 99.8 \%, Alfa Aesar), poly(methyl methacrylate-co-ethylene glycol dimethacrylate) (PMMA, $8 \mu \mathrm{m}$, Aldrich) and/or poly(ethyl methacrylate) (PEMA, 35-45 $\mu \mathrm{m}$, Aldrich). This suspension was milled at $160 \mathrm{rpm}$ for 24 hours. Secondly, poly(ethylene glycol) (PEG 300, average $\mathrm{M}_{\mathrm{n}}=300$, Aldrich) and glycerol (99.5 \%, ACS, Alfa Aesar) were added as plasticisers, before poly(vinyl alcohol) (PVA, 87-89\% hydrolysed, $\mathrm{M}_{\mathrm{w}}=$ 88,000-97,000, Alfa Aesar) and poly(vinyl pyrrolidone) (PVP, average $\mathrm{M}_{\mathrm{w}}=1,300,000$, Alfa Aesar) were added as binders. These organics were mixed into the suspension at a lower speed (100 rpm for 24 hours) to avoid degradation of the binders, before a final degassing step ( $8 \mathrm{rpm}$ for 24 hours) allowed removal of trapped air which may give rise to pinholes in the cast tape. Small samples of each slurry were subjected to rheological analysis, at room temperature, using a Brookfield DV-III Ultra Rheometer, equipped with a small sample spindle (SC4-14). Data analysis was performed using the Rheocalc 3.2 software. 
Slurries were subsequently poured into the reservoir of a doctor blade until the underlying Mylar ${ }^{\circledR}$ carrier film was completely coated. The blade gap was set to $500 \mu \mathrm{m}$ and the slurries were tape cast onto the carrier film using a Richard E. Mistler TTC1200 Benchtop Caster. A casting rate of $0.48 \mathrm{~cm} \mathrm{~s}^{-1}$ was used and the tapes were allowed to dry in air under ambient conditions $\left(19^{\circ} \mathrm{C}\right.$ to $\left.22^{\circ} \mathrm{C}\right)$.

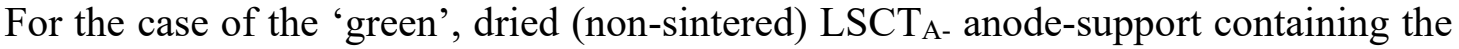
graphite pore former, an aqueous $8 \mathrm{YSZ}$ electrolyte slurry was formulated according to the above procedure (without the use of a pore former or a PVP binder) and was co-cast on top

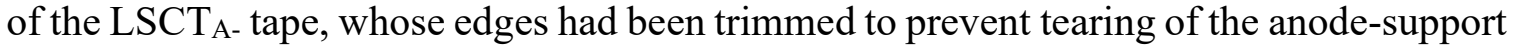
tape on the doctor blade. A blade gap of $300 \mu \mathrm{m}$ (relative to the underlying Mylar ${ }^{\circledR}$ film) was employed for the co-casting process and the electrolyte tape was allowed to dry under ambient conditions on the caster bed.

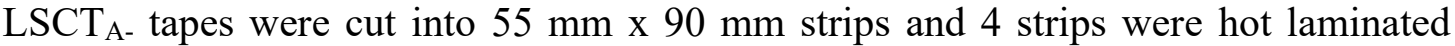
together to produce 'green' substrates onto which 8YSZ electrolytes could be screen

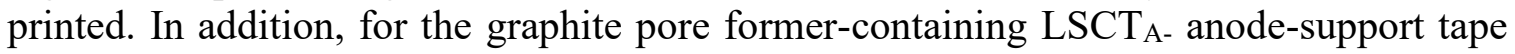
with a co-cast $8 \mathrm{YSZ}$ electrolyte, three layers of the support tape and one layer of the cocast tape were hot laminated together (with dimensions of $25 \mathrm{~mm} \times 90 \mathrm{~mm}$ ). This resulted

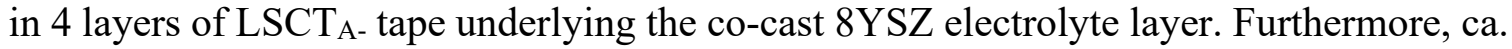
$10 \mathrm{~mm} \times 10 \mathrm{~mm}$ squares of each laminated tape (including a quadruple-laminated 8YSZ electrolyte tape) were cut in order to determine the dimensional shrinkage of the tapes upon sintering.

\section{Organic Solvent Ink Formulation and Screen Printing of Electrolytes}

An organic solvent 8 YSZ electrolyte screen printing ink was prepared using a roller ball milling and continuous agitation method. The 8YSZ powder initially underwent a dispersion milling step using a Hypermer KD1 dispersant (Croda Europe Ltd.) and an acetone solvent by roller ball milling with $3010 \mathrm{~mm}$ diameter zirconia milling media for 24 hours. Separately, a polyvinyl butyral binder (PVB, Butvar® B-98, Acros Organics) was dissolved in terpineol (anhydrous, mixture of isomers, Sigma-Aldrich) to form an organic vehicle. The 8YSZ suspension was poured into the organic vehicle and the acetone was allowed to evaporate (under stirring) at room temperature for 48 hours, yielding a 55 wt. \% solids loading 8 YSZ screen printing ink.

$8 Y S Z$ electrolyte layers were deposited onto 'green' LSCT $_{\text {A- }}$ anode supports, that had a width of $55 \mathrm{~mm}$ and a length of $90 \mathrm{~mm}$, using a DEK248 semi-automatic screen printer and a 325 mesh count (per inch) screen. Two layers of the 8YSZ electrolyte ink were deposited to form a $50 \mathrm{~mm} \times 80 \mathrm{~mm}$ printed geometry, with 30 minutes drying time at $80{ }^{\circ} \mathrm{C}$ between the deposition of each layer. All 'green' anode-electrolyte bilayers, including co-cast bilayers and anode-support tapes without deposited electrolytes, were sintered between porous alumina plates in air at temperatures between $1350{ }^{\circ} \mathrm{C}$ and $1400{ }^{\circ} \mathrm{C}$ for 2 to 5 hours. A ramp rate of $1{ }^{\circ} \mathrm{C} \mathrm{min}^{-1}$ was employed during the organic burnout stages, whilst a ramp rate of $3{ }^{\circ} \mathrm{C} \mathrm{min}^{-1}$ was employed thereafter for reaching the sintering temperature and cool down. 


\section{Thermogravimetric Analysis of Tapes and Inks}

The burnout characteristics of organic components and pore formers within each anodesupport slurry and the organic solvent 8YSZ electrolyte ink were determined by thermogravimetric analysis (TGA), using a Netzsch STA 449C Jupiter instrument. Pieces of 'green', dried anode-support tapes and 8YSZ ink ( $\sim 80 \mathrm{mg}$ each) were placed into an alumina crucible, before being loaded into the instrument. Samples were heated from $35^{\circ} \mathrm{C}$ to $1000{ }^{\circ} \mathrm{C}$ (followed by a 1 hour dwell) at a ramp rate of $3{ }^{\circ} \mathrm{C} \mathrm{min}^{-1}$ in a $50 \mathrm{~mL} \mathrm{~min}-1$ flow of compressed air. Subsequent data analysis was performed using the Netzsch Proteus ${ }^{\circledR}$ thermal analysis software.

\section{Microstructural Analysis}

Scanning Electron Microscopy (SEM) was carried out using a JEOL JSM-IT200 SEM.

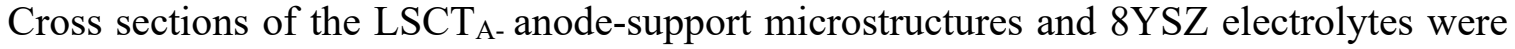
prepared by vacuum encapsulation within epoxy resin and diamond polishing once cured. Subsequently, porosity and thickness measurements were performed on obtained SE micrographs using the threshold and length scale calibration functions of the ImageJ software.

\section{Results and Discussion}

\section{Physical and Thermal Characterisation of Raw Materials}

Analysis of the particle size distribution (PSD) of a variety of electrolyte materials

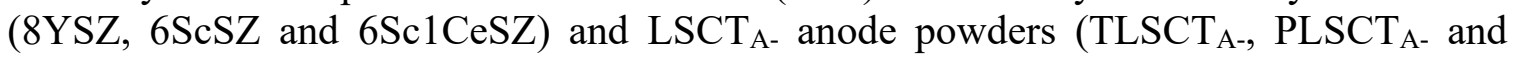
milled TLSCT $_{\mathrm{A}}$ ) was performed in order to determine $\mathrm{d}_{10}, \mathrm{~d}_{50}$ and $\mathrm{d}_{90}$ values. Figure $\mathrm{I}$ displays the PSD for each material, whilst table I summarises the aforementioned values. Both $8 \mathrm{YSZ}$ and $6 \mathrm{ScSZ}$ electrolyte powders exhibit bimodal distributions, though the fractions of the latter were significantly finer than those of 8YSZ. In comparison, the 6Sc1CeSZ powder exhibited a monomodal distribution at $0.95 \mu \mathrm{m}$. These initial results suggested that the $8 \mathrm{YSZ}$ and $6 \mathrm{ScSZ}$ powders may show a higher sinteractivity, including a better ability to densify, than the $6 \mathrm{Sc} 1 \mathrm{CeSZ}$ powder and would most likely require higher loadings of dispersant to form a homogeneous tape casting slurry. Considering the $\operatorname{LSCT}_{\mathrm{A} \text { - }}$ anode-support powders, the TLSCT $\mathrm{A}_{\mathrm{A}}$ appeared to be very coarse, with a monomodal distribution and a $\mathrm{d}_{50}$ value of $1.74 \mu \mathrm{m}$ (as also shown in previous research into ESC) (23, 24). However, the bimodal distributions of the milled TLSCT $\mathrm{A}_{\mathrm{A}}$ and $\mathrm{PLSCT}_{\mathrm{A}-\text { powders }}$ gave rise to $\mathrm{d}_{50}$ values of $0.505 \mu \mathrm{m}$ and $0.323 \mu \mathrm{m}$, respectively.

TABLE I. A summary of parameters determined from particle size analysis of the electrolyte and anodesupport powders employed in this study.

\begin{tabular}{cccc}
\hline Material & $\mathbf{d}_{\mathbf{1 0}} / \boldsymbol{\mu m}$ & $\mathbf{d}_{\mathbf{5 0}} / \boldsymbol{\mu m}$ & $\mathbf{d} \mathbf{m} / \boldsymbol{\mu m}$ \\
\hline $8 \mathrm{YSZ}$ & 0.129 & 0.461 & 1.953 \\
$6 \mathrm{ScSZ}$ & 0.09 & 0.196 & 0.681 \\
$6 \mathrm{Sc} 1 \mathrm{CeSZ}$ & 0.493 & 1.02 & 2.098 \\
PLSCT $_{\mathrm{A}-}$ & 0.107 & 0.323 & 1.554 \\
TLSCT $_{\mathrm{A}-}$ & 1.012 & 1.742 & 2.885 \\
Milled TLSCT $_{\mathrm{A}-}$ & 0.122 & 0.505 & 1.739 \\
\hline
\end{tabular}




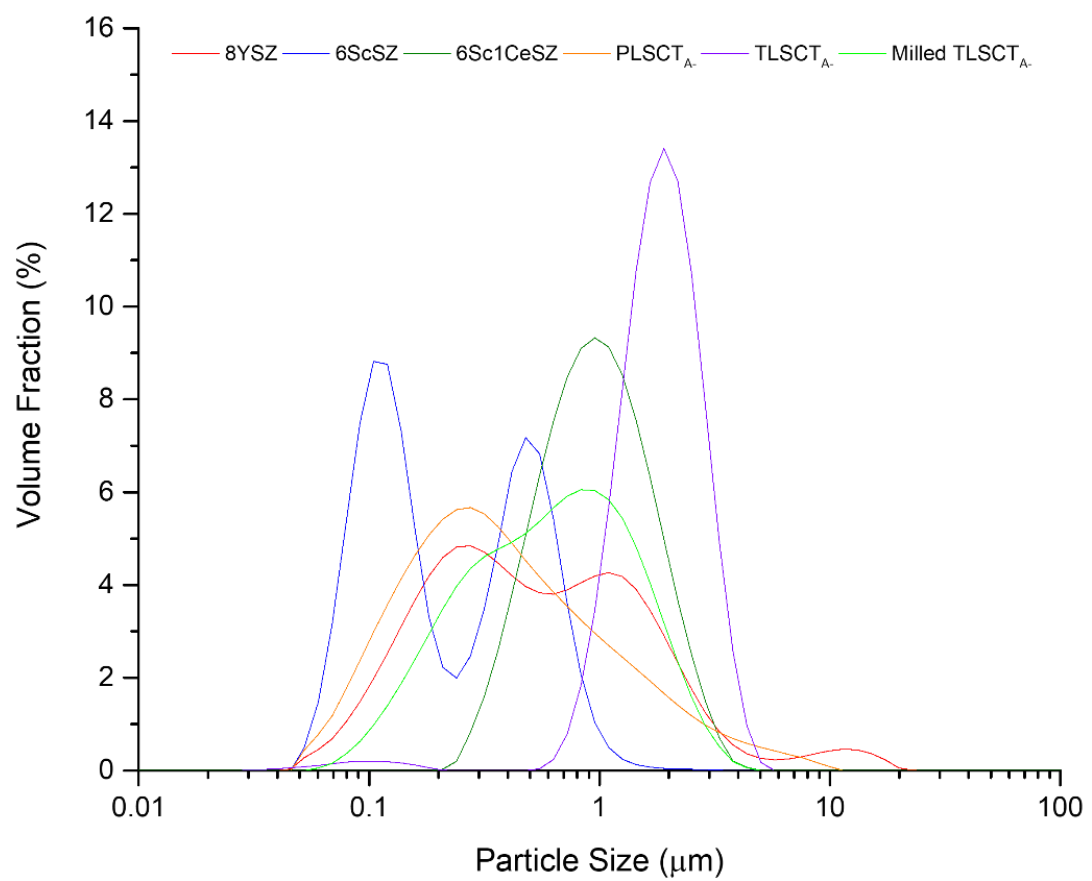

Figure I. Particle size distributions for a variety of electrolyte powders and $\mathrm{LSCT}_{\mathrm{A}-\text { anode powders employed }}$ in this study.

Subsequent dilatometric analysis of these material sets was carried out upon heating to $1350{ }^{\circ} \mathrm{C}$ (for a 3 hour dwell) and cooling (figure II). The sintering profiles of electrolyte materials indicated that the final shrinkage was much higher for 8YSZ (22.5\%) and 6ScSZ $(18.3 \%)$ than for $6 \mathrm{Sc} 1 \mathrm{CeSZ}(14.4 \%)$, whose densification process had clearly not concluded under these conditions. By contrast, the 6ScSZ and 8YSZ materials exhibit typical two-stage sintering (and densification) process observed for such electrolyte materials: an initial rapid shrinkage phase (with an onset temperature of $800^{\circ} \mathrm{C}$ and $950{ }^{\circ} \mathrm{C}$, respectively) and a secondary, slower sintering phase ensuing at $1225{ }^{\circ} \mathrm{C}$ and $1300{ }^{\circ} \mathrm{C}$, respectively. Achievement of densification through this two-stage sintering profile is crucial in ensuring the gas tightness of the relatively thin $(<20 \mu \mathrm{m})$ electrolyte layers in ASC, therefore, only $8 \mathrm{YSZ}$ and $6 \mathrm{ScSZ}$ were considered as viable candidates for electrolyte materials in this study. Examination of the shrinkage profiles of the $\mathrm{LSCT}_{\mathrm{A}}$-anode-support

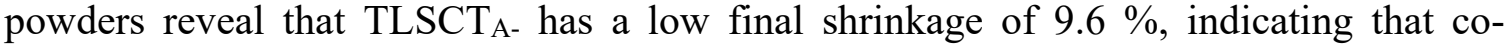
sintering with either the $6 \mathrm{ScSZ}$ or $8 \mathrm{YSZ}$ electrolyte materials would most-likely not be possible, due to large mismatch in shrinkage between these material sets.

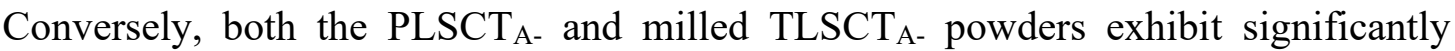
higher shrinkages (19.3\% and $20.8 \%$, respectively), making them more appropriate for co-sintering with the $8 \mathrm{YSZ}$ and $6 \mathrm{ScSZ}$ electrolytes. Initially, it may be thought that the similarity between the final shrinkages of $6 \mathrm{ScSZ}$ and $\mathrm{PLSCT}_{\mathrm{A}-}$ would give rise to successful co-sintering of the anode-support and electrolyte layers. However, the maximum rate of shrinkage for the $6 \mathrm{ScSZ}$ powder occurs at approximately $1173{ }^{\circ} \mathrm{C}$, in

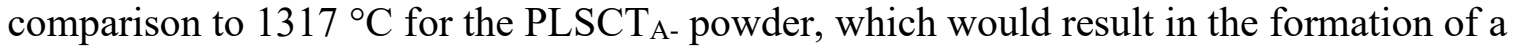
rigid $6 \mathrm{ScSZ}$ layer, that is subsequently, warped and cracked by the higher temperature

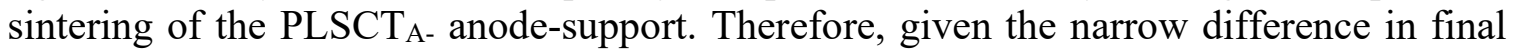

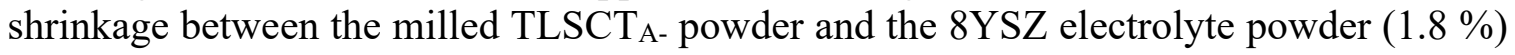
and the improved matching of the temperatures at which the maximum shrinkage rate 
occurs (1349 ${ }^{\circ} \mathrm{C}$ versus $1279{ }^{\circ} \mathrm{C}$, respectively), these anode-support and electrolyte powders were selected to be the most appropriate to for further development.

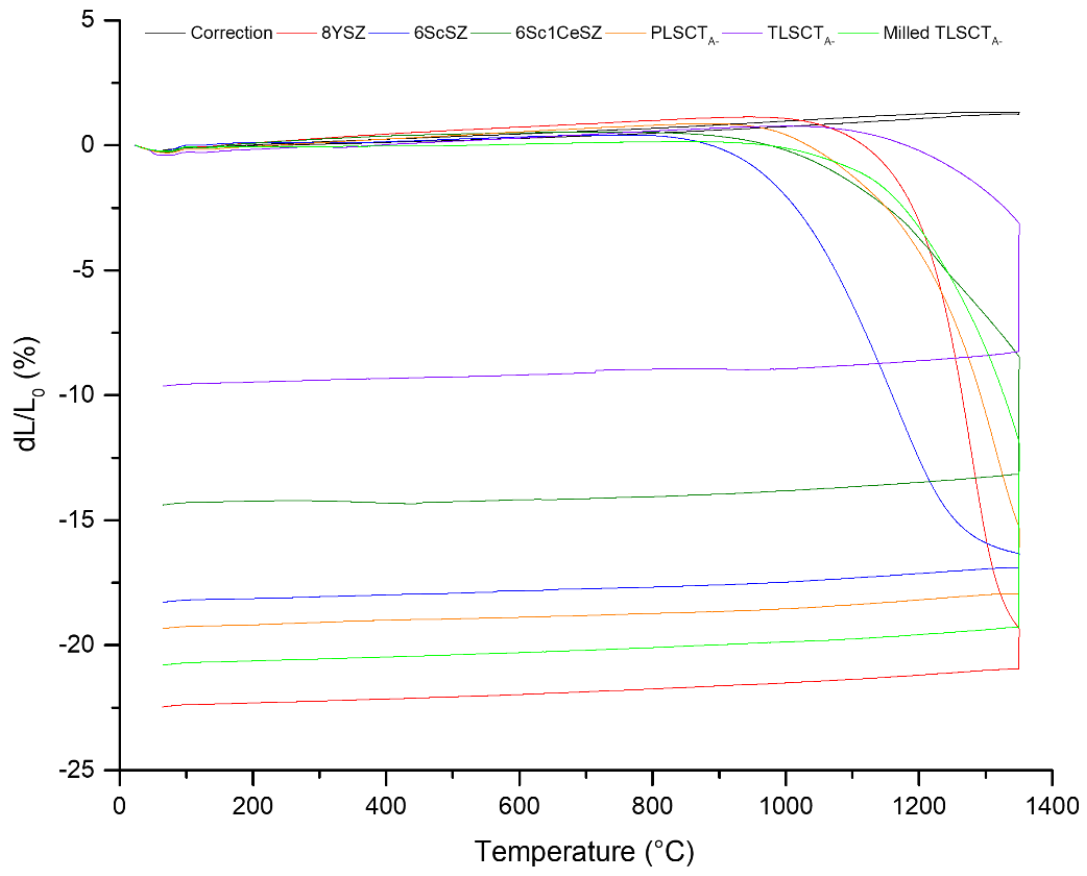

Figure II. Sintering profiles of electrolyte and $\mathrm{LSCT}_{\mathrm{A}}$ - anode-support powders obtained from dilatometric analysis upon heating to $1350^{\circ} \mathrm{C}$ (for a 3 hour dwell) and cooling, under a flow of compressed air.

\section{Evaluation of Co-Cast versus Screen Printed Electrolytes}

Aqueous slurry formulations developed by Lu et al. (20) were employed as a starting

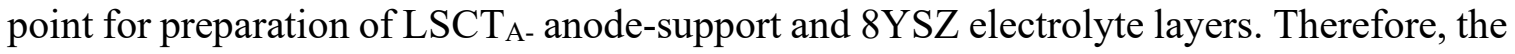

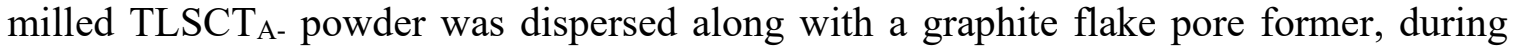
slurry formulation, to provide comparability to previous work. Tape casting of this slurry gave rise to an anode-support that exhibited few pinholes or defects at the surface, good adhesion to the Mylar ${ }^{\circledR}$ carrier film and excellent strength and handleability of the 'green' tape. Co-casting of the 8YSZ electrolyte layer onto the 'green', dried LSCT A- anodesupport tape was successful and did not result in significant re-dissolution of the binders or plasticisers in the underlying tape. This gave rise to a well-formed co-cast unit comprising a single layer of milled TLSCT $_{\mathrm{A}-}$ (with graphite pore former) and a single layer of 8 YSZ electrolyte. Hot lamination of this co-cast unit to three additional layers of the anode-support tape produced a 'green' anode-electrolyte bilayer. In addition, four layers of the anode support tape were hot laminated together, before an 8YSZ electrolyte layer was deposited by screen printing using an organic ink. The two 'green' bilayers were then co-sintered at $1350{ }^{\circ} \mathrm{C}$ for 2 hours (in air) with the aim of producing a porous anode-support microstructure strongly bound to a dense electrolyte, exhibiting equivalent thicknesses of anode-support 'backbone'. Figure III displays backscattered electron (BSE) micrographs of the sintered bilayers with electrolytes deposited by screen printing (a) and co-casting (b). The thicknesses of the anode-supports in figures III a and b were comparable $(287 \mu \mathrm{m}$ and $297 \mu \mathrm{m}$, respectively), as expected, however, the electrolyte produced by co-casting was substantially thicker than the equivalent electrolyte deposited by screen printing ( 31

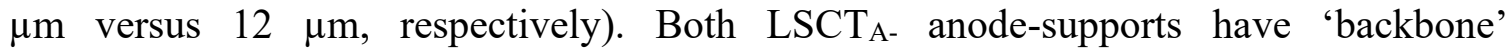
microstructures with high open porosities $(\sim 50 \%)$ and large plate-like pores produced by 
the burnout of the graphite flakes, whose long axes typically align with casting direction. Considering the 8YSZ electrolytes, though, a large amount of residual porosity also appears to have been retained in both of these layers, which would give rise to leakage and mixing of fuel and air during SOFC testing. Therefore, further optimisation of sintering conditions (temperature and dwell time) was required in order to obtain a density of electrolyte that could be employed during SOFC testing. As the screen printed electrolyte showed good adhesion to the anode-support and a much lower thickness than the co-cast variant, this thick-film deposition technique was selected for further sintering and slurry formulation trials.

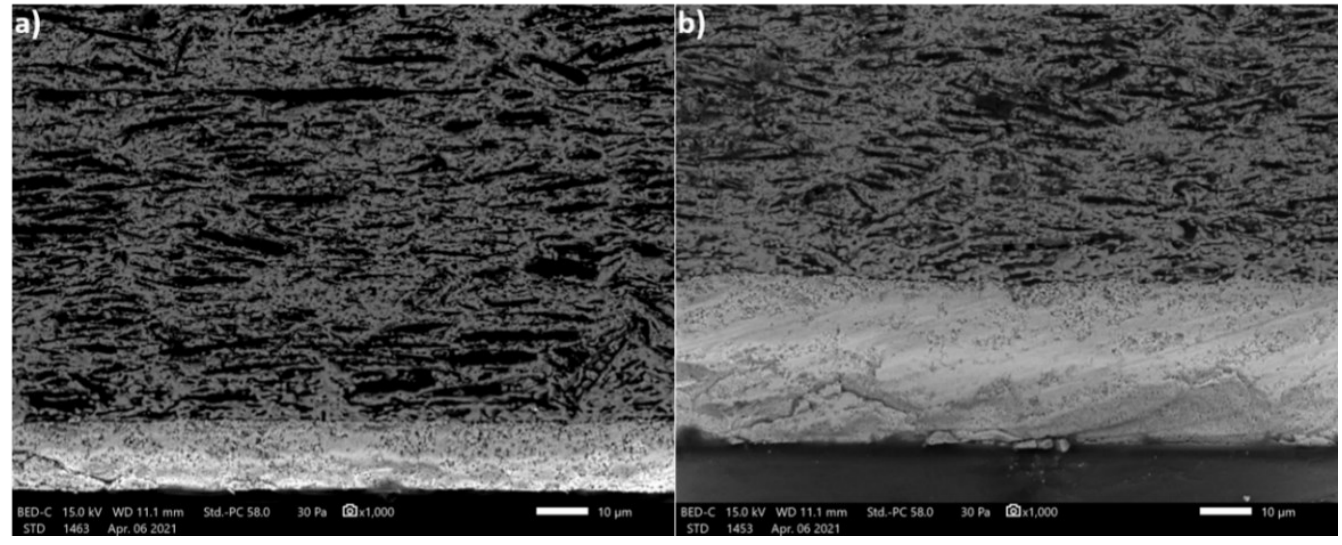

Figure III. BSE micrographs of anode-electrolyte bilayers co-sintered at $1350{ }^{\circ} \mathrm{C}$ for 2 hours, in air, whose electrolytes were deposited by a) screen printing and b) co-casting.

\section{Determination of Optimal Sintering Conditions}

A further three anode-electrolyte bilayers, produced using the tape containing milled

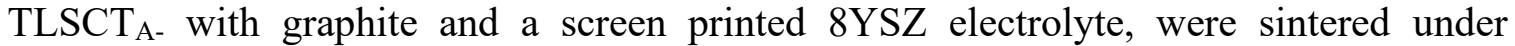
differing temperature and dwell conditions. Figure IV shows BSE micrographs of the bilayers sintered at: a) $1350{ }^{\circ} \mathrm{C}$ for 2 hours, b) $1350{ }^{\circ} \mathrm{C}$ for 5 hours, c) $1400{ }^{\circ} \mathrm{C}$ for 2 hours and d) $1400{ }^{\circ} \mathrm{C}$ for 5 hours. The micrographs of the anode-electrolyte interface of each bilayer indicate that although the density of the $\mathrm{LSCT}_{\mathrm{A}-}$ 'backbone' increases with sintering temperature and dwell time, sufficient porosity for gas diffusion and catalyst impregnation is retained. In terms of the electrolyte density, little improvement is observed when increasing the dwell time from 2 to 5 hours at a sintering temperature of $1350{ }^{\circ} \mathrm{C}$. However, increasing the sintering temperature to $1400{ }^{\circ} \mathrm{C}$ for between 2 and 5 hours results in better densification, yielding $3.8 \%$ closed porosity when sintering at $1400{ }^{\circ} \mathrm{C}$ for 5 hours. Therefore, sintering conditions of $1400{ }^{\circ} \mathrm{C}$ for 5 hours were deemed to be appropriate for obtaining a sufficiently dense $8 \mathrm{YSZ}$ electrolyte, a strongly adhered anode-electrolyte interface and an advantageous combination of grain connectivity and porosity in the

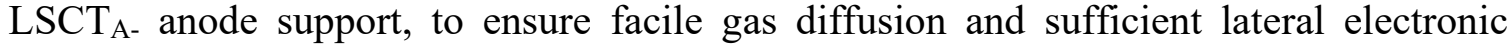
conductivity to prevent poor current distribution and degradation within the anode $(24,25)$. 


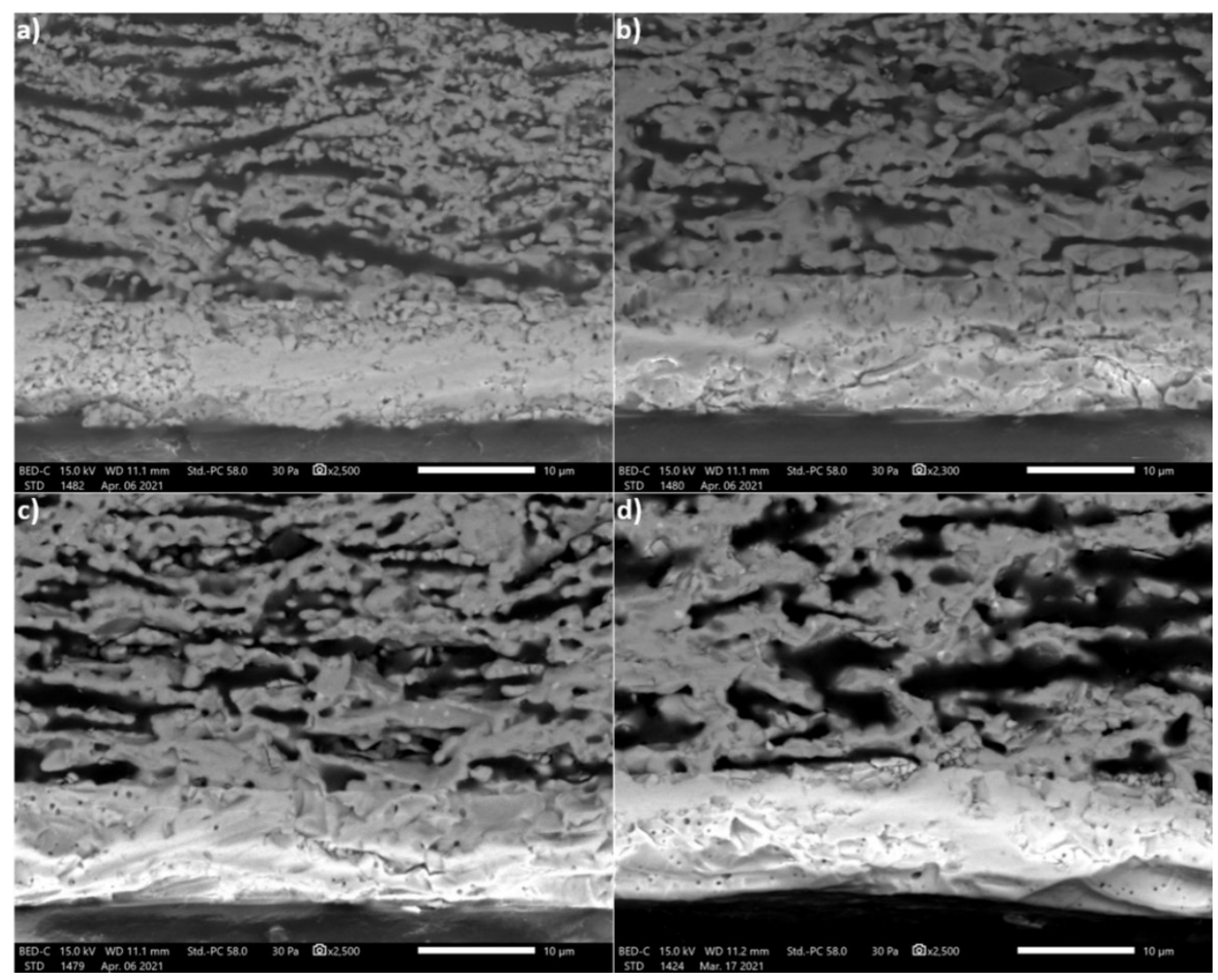

Figure IV. BSE micrographs of the anode-electrolyte interface of bilayers, produced by screen printing of an $8 \mathrm{YSZ}$ electrolyte onto an anode-support tape containing milled $\mathrm{TLSCT}_{\mathrm{A}-}$ with a graphite pore former, sintered at: a) $1350{ }^{\circ} \mathrm{C}$ for 2 hours, b) $1350{ }^{\circ} \mathrm{C}$ for 5 hours, c) $1400{ }^{\circ} \mathrm{C}$ for 2 hours and $1400{ }^{\circ} \mathrm{C}$ for 5 hours.

\section{Effect of Pore Former on LSCTA-Anode-Support Microstructure}

In order to determine whether improved anode-support microstructure and adhesion at the anode-electrolyte interface was possible, a brief investigation into the effect of pore former type on the tape casting slurries was carried out. Initially, rheological analysis was performed in order to determine the apparent viscosity and nature of fluid behaviour of the

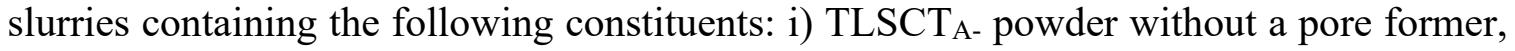

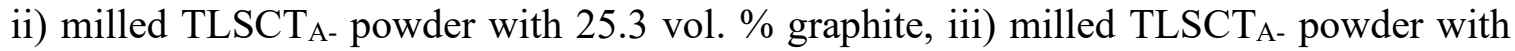

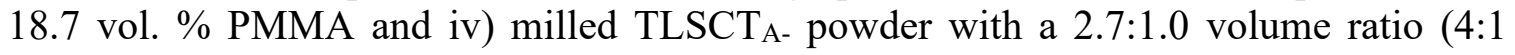
weight ratio) of PMMA:PEMA (14.7 vol. \% and 5.4 vol. \%, respectively). Figure V shows plots of shear stress versus shear rate (a) and viscosity versus shear rate (b) for each slurry. Considering the plots of shear stress versus shear rate, all slurries clearly exhibit pseudoplastic (shear-thinning) behaviour with yield stress, which is ideal for producing thicker, well-formed tapes during the tape casting process. The flow index values presented in figure $\mathrm{V}$ a confirm the pseudoplastic nature of each ink (values $<1$ arbitrary unit), whilst the hysteresis observed in the plots of shear stress versus shear rate indicates that time dependent shear-thinning, or thixotropic, behaviour is present (26). Introduction of the pore formers increased the level of thixotropy in all cases, however, the thixotropic behaviour is most pronounced in the graphite-containing specimen and is consistent with alignment of the plate-like particles of this pore former. The rheological effect of this alignment is also evidenced by the greatest level of shear-thinning behaviour (i.e. the lowest flow index) of all slurries analysed. The reduction in flow index also appears consistent with the different volume fractions of pore former in each slurry with higher volume fractions 
leading to a reduction in flow index and hence increased pseudoplasticity (22). Some level of thixotropic behaviour in these slurries can be advantageous, permitting the cast slurry to rearrange in the 'green' wet state, after passing under the doctor blade of the tape caster, allowing leveling and removal of pinholes and defects at the surface of the layer $(23,26)$.
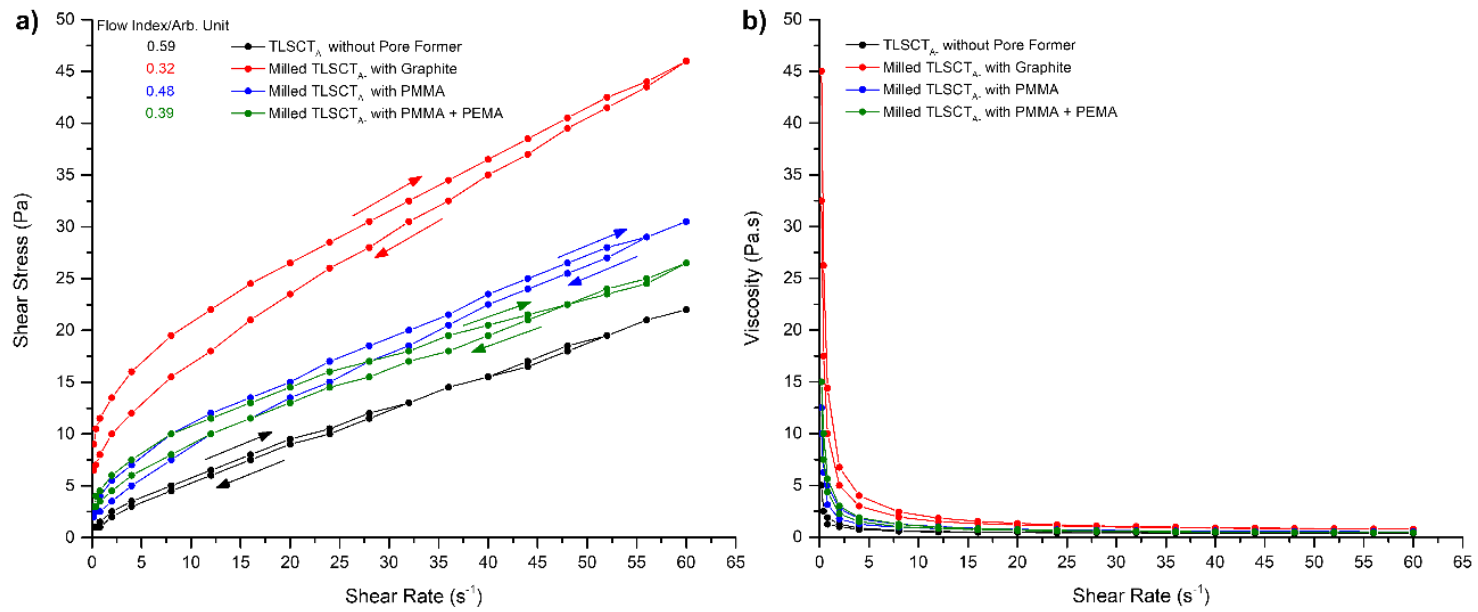

Figure V. Plots of a) shear stress versus shear rate (with accompanying flow indices) and b) viscosity versus

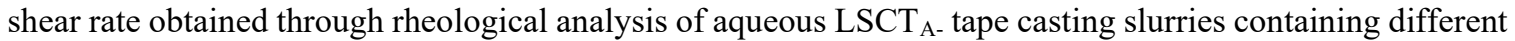
pore formers. Arrows indicate the direction of scanning and highlight hysteresis in the shear stress versus shear rate curves.

Figure VI displays cross-sectional BSE micrographs of bilayers containing anodesupports (manufactured by laminating 4 layers of tape) containing either: a) TLSCT $_{\mathrm{A}-}$

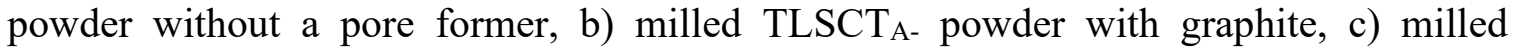

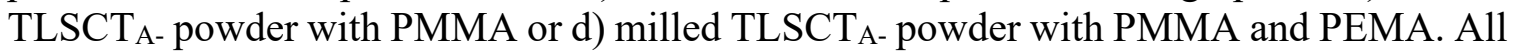
were co-sintered at $1400{ }^{\circ} \mathrm{C}$ for 5 hours. A summary of the anode and electrolyte thicknesses, along with the anode porosities, is provided in Table II. Firstly, considering the BSE micrograph in figure $\mathrm{V}$ a, the anode microstructure resulting from employment of

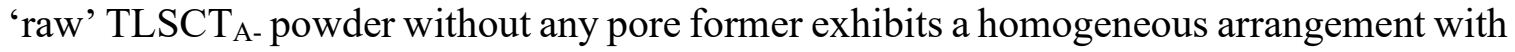
very few defects caused by non-optimal lamination and burn out of pore formers. A similar porosity of this anode-support was measured $(43.7 \%)$, in comparison to $\mathrm{LSCT}_{\mathrm{A}}$ microstructures sintered at $1350{ }^{\circ} \mathrm{C}$ for 2 hours during previous research into ESC (46.1\%) (24), with pores of $1-5 \mu \mathrm{m}$ in diameter.

In comparison, the anode microstructures obtained using the graphite flake pore former (figure VI b), spherical PMMA pore former (figure VI c) and 4:1 ratio of PMMA:PEMA pore formers (figure VI d) all exhibit some poor contact between the laminated layers due to a non-optimal hot lamination process and slippage caused by the lubricating effect of the graphite flakes, in the case of figure VI b. Whilst the microstructure of the anodesupport produced using the graphite pore former appears irregular and has a strong longitudinal alignment of larger elongated pores, smaller pores (typically between $0.5 \mu \mathrm{m}$ and $3 \mu \mathrm{m}$ diameter) are retained. This arrangement of pores within the microstructure reinforces the previous suggestion that the mechanism for the increased thixotropic behaviour of this slurry relates to alignment of the graphite flake pore former in the 'green', wet layers. In contrast, the microstructures produced as a result of methacrylate pore former inclusion give larger, more spherical pores at the expense of porosity on the micron scale, which may result in a less homogeneous distribution of catalyst phases during the process of wet impregnation. Another issue posed by the microstructures that result from aqueous- 
compatible pore former inclusion is that non-optimal burnout often leaves behind voids that could detrimentally impact the mechanical strength of the anode-support material, especially during the SOFC stacking process. Therefore, the most advantageous $\mathrm{LSCT}_{\mathrm{A}-}$ anode-support microstructure for high mechanical strength (in addition to facile catalyst

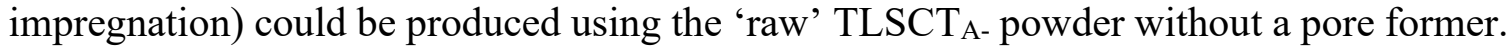

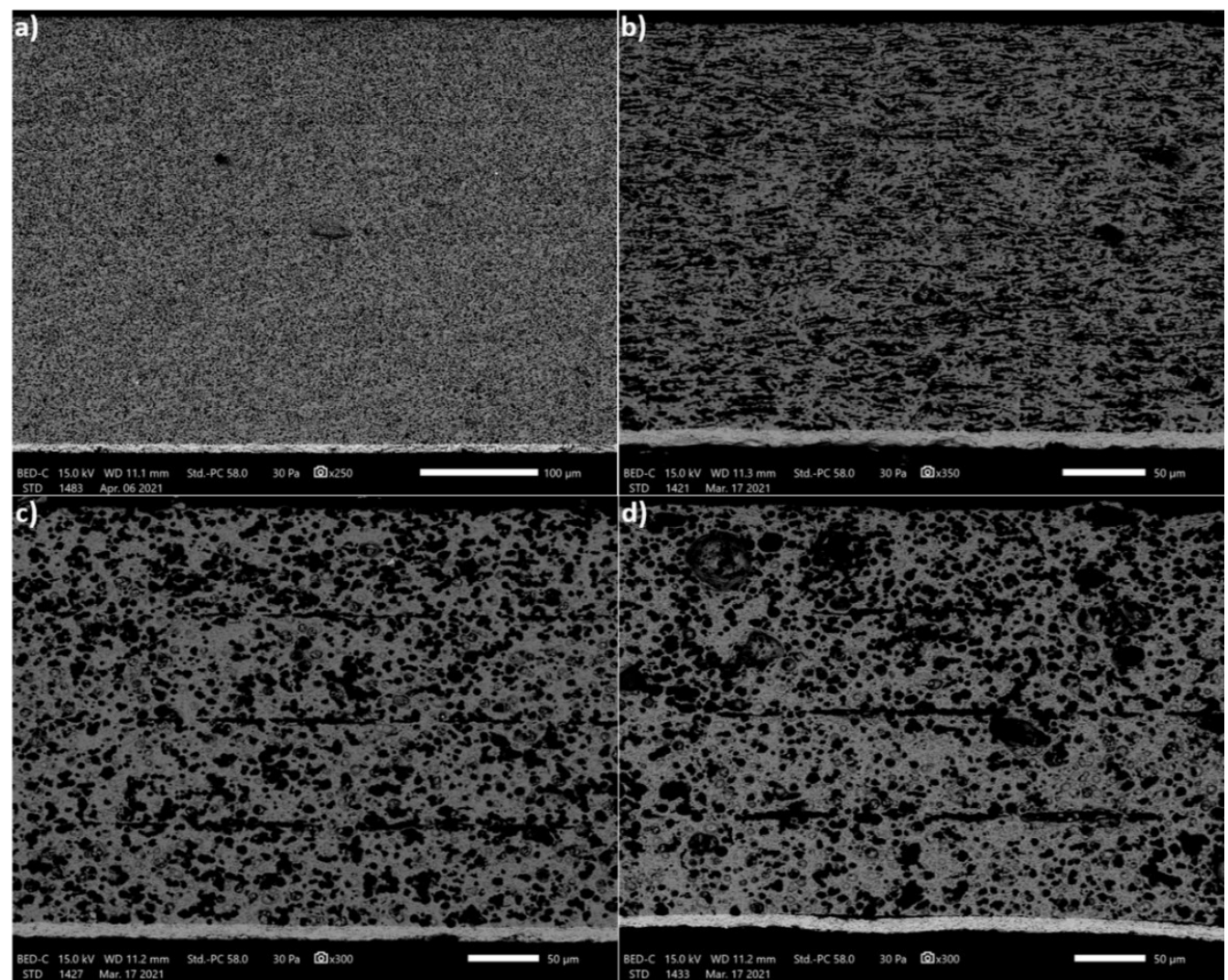

Figure VI. BSE micrographs of the anode-electrolyte bilayers, produced by screen printing of an $8 \mathrm{YSZ}$ electrolyte onto an anode-support tape containing a) TLSCT $_{\mathrm{A}}$ - without a pore former, b) milled TLSCT $\mathrm{A}_{\mathrm{A}}$

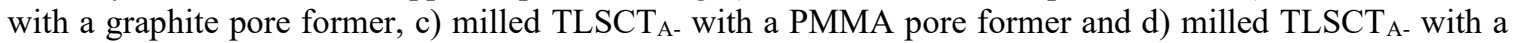
2.7:1 volume ratio of PMMA:PEMA pore formers, sintered at $1400^{\circ} \mathrm{C}$ for 5 hours.

TABLE II. A summary of average anode and electrolyte thicknesses, as well as anode porosities, for LSCT $_{\mathrm{A}-}$ /8YSZ bilayers produced using differing anode-support pore formers after sintering at $1400{ }^{\circ} \mathrm{C}$ for 5 hours in air.

\begin{tabular}{|c|c|c|c|}
\hline LSCT $_{\text {A- }}$ Powder Type/Pore Former & $\begin{array}{l}\text { Average Anode } \\
\text { Thickness/ } \mu \mathrm{m}\end{array}$ & $\begin{array}{l}\text { Average Electrolyte } \\
\text { Thickness/ } \mu \mathrm{m}\end{array}$ & Anode Porosity $/ \%$ \\
\hline TLSCT $_{\mathrm{A}-} /$ None & 366 & 8 & 43.7 \\
\hline Milled TLSCT $\mathrm{A}_{\mathrm{A}} /$ Graphite & 251 & 9 & 45.2 \\
\hline Milled TLSCT $\mathrm{A}_{\mathrm{A}} / \mathrm{PMMA}$ & 302 & 10 & 47.0 \\
\hline Milled TLSCT ${ }_{A}$-/PMMA:PEMA & 296 & 9 & 47.6 \\
\hline
\end{tabular}

Subsequently, analysis of the dimensional shrinkage of $\sim 10 \mathrm{~mm} x \sim 10 \mathrm{~mm}$ squares of each separate anode-support tape, in addition to an 8YSZ electrolyte tape, highlighted several important observations. The physical observations and average dimensional shrinkages of each tape are summarized in table III. As previously highlighted during

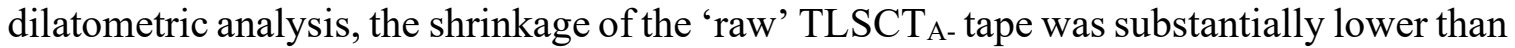
that of the $8 \mathrm{YSZ}$ tape, $24.0 \%$ versus $31.8 \%$, respectively (with the $8 \mathrm{YSZ}$ tape being used to provide an indicator of how the screen printed layers may behave). Consequently, this led to constrained sintering of the electrolyte on the anode-support and development of a 
hairline fracture propagating across the surface of the bilayer. Thus, despite the excellent flatness of this bilayer and ideal microstructural properties exhibited by this anode-support (without the use of a pore former), successful co-sintering could not be achieved. It was

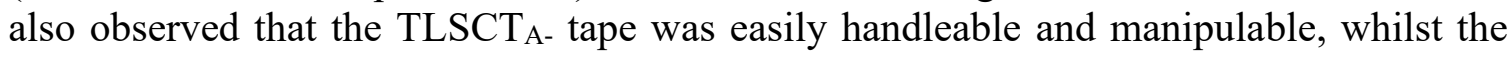
8 YSZ tape was quite fragile and ripped easily. Both tapes were formulated according to the same recipe, without the use of pore formers, but with the exception that the TLSCT $\mathrm{A}$ tape contained a low loading of additional PVP binder. This good handleability was also

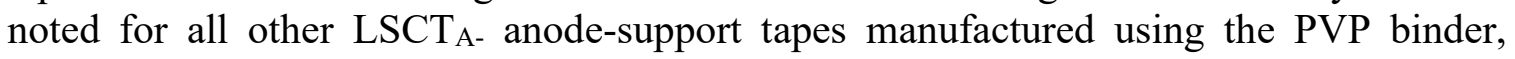
therefore, this suggests that the PVP component gives rise to substantially improved handleability and adhesion.

TABLE III. A summary of average dimensional shrinkage of each anode-support tape and 8YSZ electrolyte tape, as well as physical observations of bilayers, after sintering at $1400{ }^{\circ} \mathrm{C}$ for 5 hours in air.

\begin{tabular}{|c|c|c|}
\hline Powder Type/Pore Former & $\begin{array}{l}\text { Average Dimensional } \\
\text { Shrinkage } / \%\end{array}$ & $\begin{array}{l}\text { Physical Observations of } \text { LSCT }_{A-} \\
\text { /8YSZ Bilayers }\end{array}$ \\
\hline TLSCT $_{\mathrm{A}-/ \text { None }}$ & 24.0 & Hairline fracture across entire bilayer \\
\hline Milled TLSCT $\mathrm{A}_{\mathrm{A}} /$ Graphite & 29.0 & $\begin{array}{c}\text { Flat bilayer, good anode-electrolyte } \\
\text { adhesion }\end{array}$ \\
\hline Milled TLSCT $\mathrm{A}_{\mathrm{A}} / \mathrm{PMMA}$ & 33.4 & $\begin{array}{l}\text { Flat anode-support, wrinkling and } \\
\text { delamination of electrolyte at outer } \\
\text { edge of bilayer }\end{array}$ \\
\hline Milled TLSCT $\mathrm{T}_{\mathrm{A}-} / \mathrm{PMMA}$ :PEMA & 33.1 & $\begin{array}{l}\text { Flat anode-support, complete } \\
\text { wrinkling and delamination of } \\
\text { electrolyte }\end{array}$ \\
\hline 8YSZ/None & 31.8 & - \\
\hline
\end{tabular}

Although the bilayers produced using the methacrylate polymer pore formers yielded flat substrates, the screen printed 8YSZ electrolyte layer delaminated at the edges of the anode-support containing the PMMA pore former, whilst severe 'wrinkling' of the electrolyte was observed for the anode-support employing the 2.7:1 volume ratio mixture of PMMA:PEMA (displayed in figure VII). As the dimensional shrinkages of these tapes matched well to that of the $8 \mathrm{YSZ}$ tape, it was postulated that differences in the temperatures of pore former burnout, from 'green' anode layers, and dispersant/binder burnout from screen printed electrolyte layers, could have given rise to poor adhesion between these functional layers. However, thermogravimetric analysis (TGA) of each anode-support tape and the dried 8 YSZ screen printing ink (figure VIII) indicated that all organic components (i.e. binders, dispersants, plasticisers and methacrylate polymer pore formers) exhibited a complete, clean burnout upon heating to $440{ }^{\circ} \mathrm{C}$, whilst the graphitic pore former combusted between $414{ }^{\circ} \mathrm{C}$ and $890^{\circ} \mathrm{C}$. Therefore, it is most likely that the microstructural voids left behind as a result of burnout of the methacrylate polymer pore formers promoted loss of porosity on the micron scale during sintering of the $\mathrm{LSCT}_{\mathrm{A}-}$ 'backbones', causing increased local shrinkage, retention of only $\sim 8 \mu \mathrm{m}$ pores and deformation of the thinner electrolyte layer at the surface. It should be noted that the variations in the residual masses of each sample, displayed in figure VIII, reflect differences in the initial ceramics loading of the 'green', dried $\mathrm{LSCT}_{\mathrm{A}-}$ tapes with pore formers $(55.9 \mathrm{wt} . \%)$ and without pore formers $(76.9 \%)$, as well as the 'green', dried 8YSZ ink (97.0\%). Finally, the dimensional shrinkage of the $\mathrm{LSCT}_{\mathrm{A}}$ - anode-support produced using the graphite pore former was sufficiently matched to that of 8YSZ to allow co-sintering of these two layers, yielding a flat cell without cracks and a well-adhered anode-electrolyte interface. Therefore, although the anode-support microstructure obtained using this pore former is not optimal, it provides the most advantageous bilayer substrate, whose anode could be impregnated with 
electrocatalysts and onto which a cathode could be deposited for SOFC testing under realistic operating conditions.

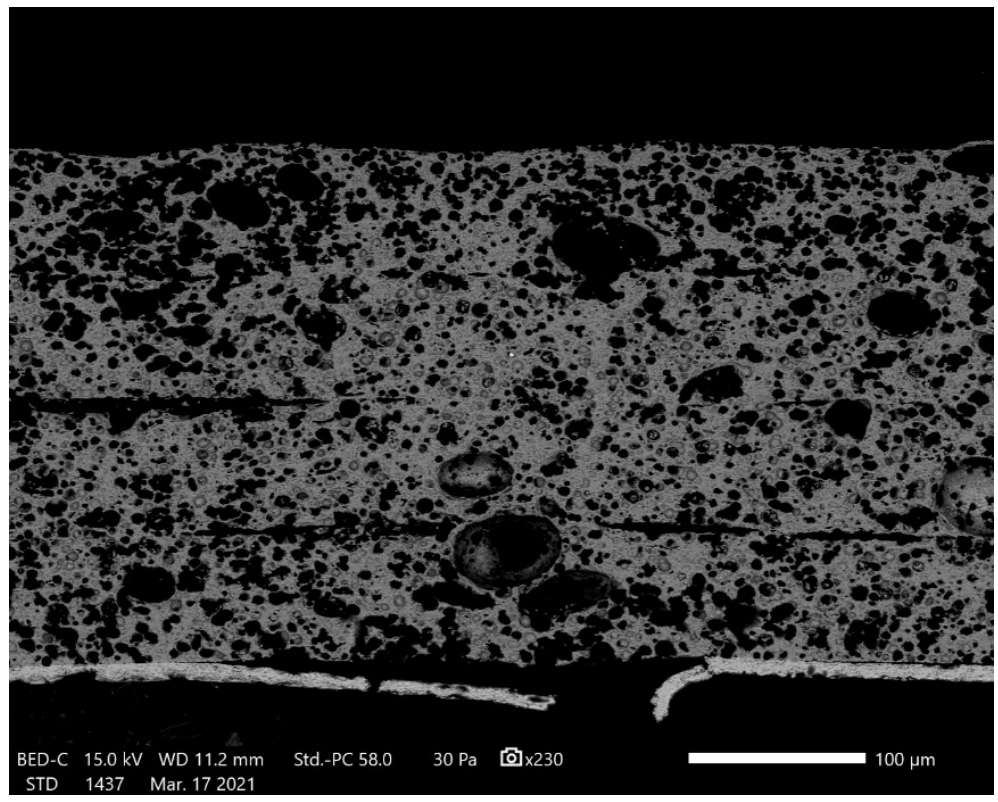

Figure VII. BSE micrograph of the bilayer produced using the milled TLSCT $_{\mathrm{A}-\text { powder with a } 2.7: 1 \text { volume }}$ ratio of PMMA:PEMA pore formers sintered at $1400{ }^{\circ} \mathrm{C}$ for 5 hours in air, exhibiting severe delamination at the anode-electrolyte interface.

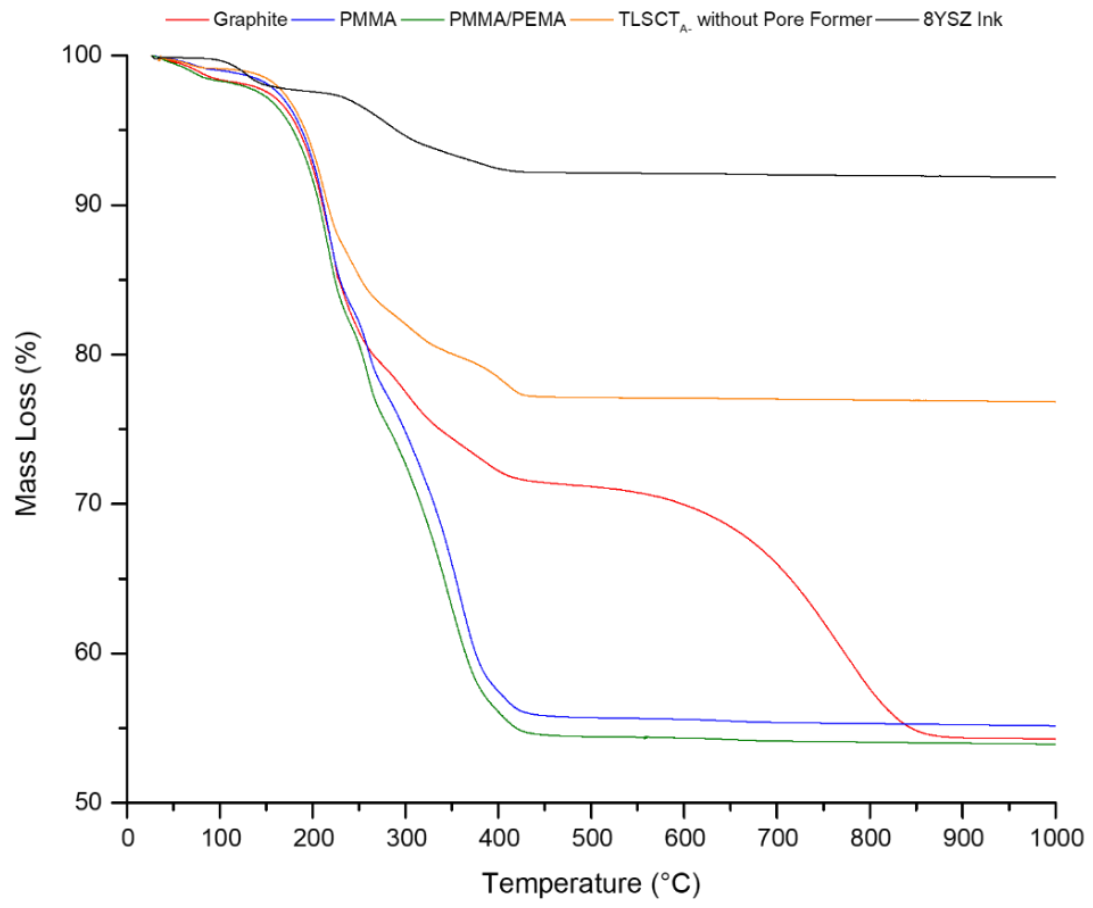

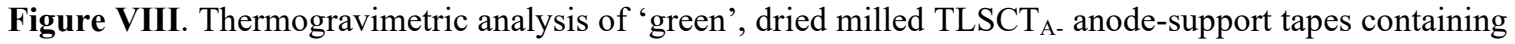

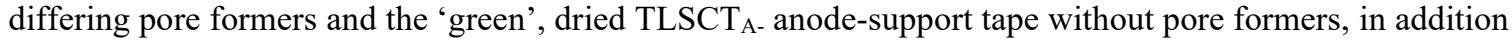
to the 'green', dried 8 YSZ screen printing ink. 


\section{Conclusions}

An investigation of the incorporation of $\mathrm{LSCT}_{\mathrm{A}-}$ into anode-supports, for use in SOFC, has been performed. Thermal compatibility studies, using dilatometric analysis, indicated

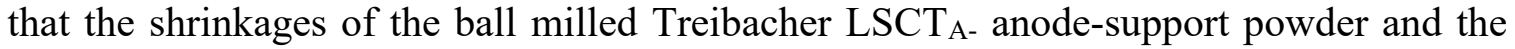
8YSZ electrolyte powder were sufficiently matched to allow co-sintering of bilayers up to $1350{ }^{\circ} \mathrm{C}$. Aqueous slurry formulation and tape casting of this $\mathrm{LSCT}_{\mathrm{A}-\mathrm{p}}$ powder, using a graphite flake pore former, yielded a smooth 'green' tape with few pinholes or surface

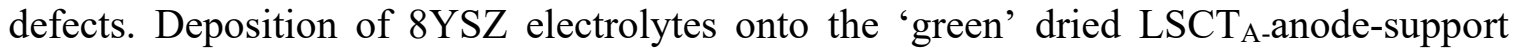
tapes using an aqueous co-casting slurry (31 $\mu \mathrm{m}$ electrolyte layer) and an organic solvent screen printing ink (12 $\mu \mathrm{m}$ electrolyte layer) showed that a much thinner electrolyte layer could be obtained using the screen printing method, after sintering at $1350{ }^{\circ} \mathrm{C}$ for 2 hours in air. However, co-sintering conditions of $1400{ }^{\circ} \mathrm{C}$ for 5 hours were required in order to achieve a density of electrolyte that would ensure gas tightness during future fuel cell testing. Finally, variation of the type of pore former employed during aqueous slurry formulation of the milled Treibacher $\mathrm{LSCT}_{\mathrm{A}-}$ powder illustrated that, under identical sintering conditions, PMMA and PEMA pore formers gave rise to microstructures with larger, more spherical pores (at the expense of pores in the $0.5-3 \mu \mathrm{m}$ range) but exhibited delamination of the electrolyte layer. In contrast, the graphite flake pore former allowed retention of pores in this size range, in addition to providing larger elongated pores and good adhesion to the electrolyte. Use of the 'raw' Treibacher LSCT $\mathrm{A}$ - powder without a pore former gave rise to a homogeneous microstructure with ideal characteristics for gas diffusion and catalyst impregnation, however, due to the mismatch in sintering shrinkages between the anode and electrolyte powders, co-sintering could not be realised. Future work will focus on optimisation of the size, shape and distribution of pores within the $\mathrm{LSCT}_{\mathrm{A}}$ anode-support microstructure by utilisation of pore former mixtures comprising graphite with low loadings of PMMA. Furthermore, implementation and testing of the optimised anode microstructure in a full anode-supported SOFC, whose anode could be impregnated with uniformly distributed Rh and CGO20 catalysts, will be targeted.

\section{Acknowledgements}

We would like to thank Dr Holger Bausinger, Dr Jan G. Grolig and Dr Andreas Mai for supporting this research and providing materials, as well as HEXIS AG and the EPSRC projects: EP/L017008/1 "Capital for Great Technologies"; EP/ P024807/1 "Hydrogen and Fuel Cells Hub" for funding.

\section{References}

1. P. Holtappels and U. Stimming, in Handbook of Fuel Cells - Fundamentals, Technology and Applications, W. Vielstich, A. Lamm and H. A. Gasteiger, Editors, p. 335, John Wiley \& Sons, Chichester (2003).

2. J. H. Hirschenhofer, D. B. Stauffer, R. R. Engleman and M. G. Klett, Fuel Cell Handbook, p. 5-1, Parsons Corporation, Reading (1998).

3. C. Sun and U. Stimming, J. Power Sources, 171, 247 (2007).

4. B. Iwanschitz, J. Sfeir, A. Mai and M. Schütze, J. Electrochem. Soc., 157, B269 
(2010).

5. N. Q. Minh, J. Am. Ceram. Soc., 76, 563 (1993).

6. M. Cassidy, G. Lindsay and K. Kendall, J. Power Sources, 61, 189 (1996).

7. B. C. H. Steele, Solid State Ionics, 129, 95 (2000).

8. M. J. Jørgensen and M. Mogensen, J. Electrochem. Soc., 148, A433 (2001).

9. S. P. Jiang, Solid State Ionics, 146, 1 (2002).

10. J. A. Kilner and M. Burriel, Annu. Rev. Mater. Res., 44, 365 (2014).

11. A. Mai, V. A. C. Haanappel, S. Uhlenbruck, F. Tietz and D. Stöver, Solid State Ionics, 176, $1341(2005)$.

12. A. Mai, V. A. C. Haanappel, F. Tietz and D. Stöver, Solid State Ionics, 177, 2103 (2006).

13. E. Perry Murray, M. J. Sever and S. A. Barnett, Solid State Ionics, 148, 27 (2002).

14. F. Tietz, V. A. C. Haanappel, A. Mai, J. Mertens and D. Stöver, J. Power Sources, 156, 20 (2006).

15. A. Esquirol, N. P. Brandon, J. A. Kilner and M. Mogensen, J. Electrochem. Soc., 151, A1847 (2004).

16. A. Faes, A. Hessler-Wyser, A. Zryd and J. Van Herle, Membranes, 2, 585 (2012).

17. R. Price, M. Cassidy, J. G. Grolig, G. Longo, U. Weissen, A. Mai and J. T. S. Irvine, Adv. Energy Mater., 11, 2003951, (2021).

18. V. Vasechko, M. Ziegner and J. Malzbender, Ceram. Int., 40, 13179 (2014).

19. M. C. Verbraeken, B. R. Sudireddy, V. Vasechko, M. Cassidy, T. Ramos, J. Malzbender, P. Holtappels and J. T. S. Irvine, J. Eur. Ceram. Soc., 38, 1663 (2018).

20. L. Lu, C. Ni, M. Cassidy and J. T. S. Irvine, J. Mater. Chem. A, 4, 11708 (2016).

21. C. Ni, L. Lu, D. N. Miller, M. Cassidy and J. T. S. Irvine, J. Mater. Chem. A, 6, 5398 (2018).

22. M. Cassidy, D. J. Doherty, X. Yue and J. T. S. Irvine, ECS Trans., 68(1), 2047 (2015).

23. R. Price, M. Cassidy, J. A. Schuler, A. Mai and J. T. S. Irvine, ECS Trans., 68(1), 1499 (2015).

24. R. Price, M. Cassidy, J. A. Schuler, A. Mai and J. T. S. Irvine, ECS Trans., 78(1), 1385 (2017).

25. M. C. Verbraeken, B. Iwanschitz, E. Stefan, M. Cassidy, U. Weissen, A. Mai and J. T. S. Irvine, Fuel Cells, 15, 682 (2015).

26. R. Mistler and E. Twiname, Tape Casting: Theory and Practice, p. 133, The American Ceramic Society, Westerville, (2000). 